\title{
Representation of Common Sense in Chinese Idioms
}

\author{
Yan Hai ${ }^{1, *}$ Haibin Dong ${ }^{1}$ \\ ${ }^{I}$ Northwest University, Xi'an, Shaanxi, China \\ "Corresponding author. Email: yanhai2020@outlook.com
}

\begin{abstract}
Speech codes help shape common sense system in a specific yet populous culture. Some culturally saturated metaphors in traditional Chinese idioms might exemplify the functions and structures of common sense in communication, becoming commonsense social norms affecting ordinary Chinese communicative behaviors by enabling, guiding, framing, constraining, strategizing, describing, interpreting, and theorizing about communication. The pool of Chinese idioms is a cultural resource that enables and constrains human relations, which are both constructs and constraints of their users' models of personhood, sociality, and understanding of communication.
\end{abstract}

Keywords: Chinese idiom, Metaphor, Common sense, Communication.

\section{INTRODUCTION}

Common sense seems to be very low end, less distinctive and aristocratic than abstract concepts and scientific principles, and also very formless, unsystematic, and intangible ([2], [3], [6], [10]). The elitist culture of society represented by scientists, philosophers, and other scholars also disdain common senses of common people and devote to higher levels of abstraction and more thorough extraction of ordinary knowledge common to all. But common sense, we propose, is something that actually finalizes communication ([4]). In order to facilitate the effective communication, the specific community would foster, create, produce, generalize, jargonize, or even institutionalize some common senses in both deliberate and natural ways. That's why culture is the common sense of a specific community ([8]). When pondering common sense problems, every normal and mentally healthy person has the legitimate right to make a claim since everybody gets the access to the database of common sense. Although someone might think that common sense is unscientific, many scientists now begin to study common sense of people and attempt to implant human common sense system into machine (artificial intelligence).

A speech code is one type of common sense. The phonetic representation (orality) and literal implication (textuality) of a speech code are not the only aspects that constitute the functions and structures of common sense ([6], [12]). A unique feature of common sense is its direct connection and straightforward relation to human's visual perception. By connection and relation, we mean common sense can easily cause, trigger, initiate, and ignite people's imagination of spatial memories and visual senses. It is by the visuality that common sense bridges the different ideas of different people and involves them in constant communications and debates. Common sense is one kind of conceptual system, just like metaphor, therefore, common sense and metaphor may be a pair of concepts that explain one another ([9]).

In this study, we intend to illuminate how some speech codes help shape common sense system in a specific yet populous culture. Some culturally saturated metaphors in traditional Chinese idioms might exemplify the functions and structures of common sense in communication. In Chinese language, there are approximate 13,000 traditional idioms called Chéngyŭ, literally meaning "established phrases." Most of such "established phrases" were formed naturally by usages and have been applied in everyday communications for centuries. They are simple and well-structured phrases with varieties of connotations. Chinese idioms have become commonsense social norms affecting ordinary Chinese communicative behaviors by enabling, guiding, framing, constraining, strategizing, describing, interpreting, 
and theorizing about communication. The pool of Chinese idioms is what Hall and Noguchi ([7]) means a cultural resource that enables and constrains human relations. They are both constructs and constraints of their users' models of personhood, sociality, and understanding of communication ([1]).

\section{AN EPISODE OF NEW PARENTHOOD}

Ablactation might be hard yet important for mothers and their infants. After breast-feeding their son Petrick for over one year, Xiá (the wife) felt very exhausted. She needs to warm up with her studies and needs higher quality of sleeps at night.

One prerequisite for her to achieve better sleeps is to keep away from Petrick, because he wakes up and asks for breast too many times throughout the night. Since Petrick's pediatrician told the couple breast milk doesn't have any nutritious advantage compared to formula or regular cow milk after the infant is over 9 months, the couple decided to ablactate him. At first, they just put Petrick in his crib very next to their bed.

As usual, he woke up and started crying. Partitioned by the fender bars of the crib, Petrick was so desperate to reach his mom but couldn't. The couple are both awakened by his enduring weeping and screaming. Xiá is so soft-hearted that she felt there's no way to handle the ablactation, so she just held Petrick back in her arms and fed him until he fell asleep again.

The next night, Qiáng (the husband) came forward and asked Xiá to sleep in the living room. By closing the door, Qiáng determined to confront Petrick by himself. Again, Petrick woke up at midnight and cried for breast. Qiáng just ignored his cry and held himself firm. Within 20 minutes, he curbed his impulses of caring Petrick and let him be. 45 minutes is the limit preset for him to cry. Then Qiáng held him in arms. Amazingly, Petrick fell asleep immediately in Qiáng arms without the routine pacifying process by the breast. Qiáng was so proud that he could finally handle him.

Although Qiáng is not particular henpecked, Xiá's words are certainly very effective in terms of disciplining his behaviors. So the next morning when they talked about this meaningful night, Qiáng explained this phenomenon by using a Chinese proverb: "Yí Wù Xiáng Yí Wù (one thing subdues another)." Xiá laughed and nodded to agree.
This is an important episode in this Chinese couple's experience as new parents. The use of a common sense verbal message or speech act not only naturally summarizes the phenomenon, rationalizes the latent norms of personal interaction, but also creates relaxation among family members (because they both believe "tougher love is sweeter love") and strengthens their memorization of the episode. To understand the connotation of idioms as such and be able to use them, you don't have to know the exact denotation and the source of the stories. Sometimes the memorization of the denotations might be blurred and even distorted, but people can still understand and use the idioms in the right places. Specifically, in Chinese culture, many of such established phrases serve as culturally distinctive speech code to facilitate and frame communication through the process of intervening or constituting the common sense. In the following

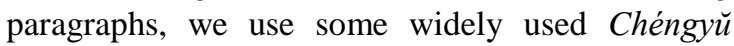
(established phrases in Chinese) as portals to describe how speech code affects communicating behaviors via textual and visual constructions of common sense in the specific community.

\section{COMMON SENSES GUIDE PEOPLE TOWARDS THE IDEAL INTERPERSONAL RELATIONSHIP}

About 3 thousand years ago, a wise man who influenced generations of Chinese in many ways wrote about his observation on interpersonal relationships: "The relationship of $J \bar{u} n Z \bar{l}$ (people of honor) is as insipid and clear as water; the relationship of XiăoRén (small people or base persons) is as juicy and sweet as rice wine. The relationship of $J \bar{u} n Z \bar{l}$ is insipid but close and the relationship of XiăoRén is sweet yet doomed (Zhuāng Ž̆, 369B.C. -286B.C.)." JūnZZ̆ , as a person of honor, has similar connotation as gentleperson or nobleperson in ancient China. Jūn $\bar{\imath} \breve{l}$ is the ideal personhood; therefore, the relationship of $J \bar{u} n Z \bar{l}$ is regarded as the ideal relationship, analogous to the quality and characteristics of water, which is tasteless but clear, insipid but free from adulterants, formless but flexible, and feint but dynamic. Ancient Chinese sages highly praise the characteristics of water and believe that people of honor with good will are always fond of water, "RénZhě Lè Shüi".

The insipidness of an ideal interpersonal relationship is reflected in terms of both material goods and physical contacts. In terms of material 
goods, the rule of insipidness is followed by people as the verbal façade to avoid valuable gifts without impairing the relationships. By physical contacts, we mean the proximity between two people during the interaction. The physical proximity doesn't mean the psychological or spiritual closeness. For "people of honor", proximity should only have the empathic, spiritual, and even intellectual connotations and have no implication of physical closeness. So Chinese people, generally, do not touch each other, although hand-shaking, one of the most popular rituals, happens often in quite formal occasions.

The characteristics of clear water could be related to the aesthetical value of simplicity, but another conventional metaphor also very popular in Chinese culture seems to counteract the value of clear water: "No fish lives in the purest water". The value of simplicity is reflected by the beauty and virtues of clear water and applied in everyday lives of common Chinese. When some people follow the rule of insipid relationship, some people take "No fish lives in the purest water" as an excuse for their misdemeanors in terms of business or social relational contexts.

\section{THE STATUS CHANGES OF COMMUNICATORS FROM POWER BROKERS TO SEWERS}

Professional communicator used to be an important job. But with the changes of history, the status of Shùi Kè (persuasive talker) has been changed from those as power brokers to someone doing sewing jobs. The identity change of professional communicator perhaps reflects how the entire nation was turning to introversive. Such changing identity status could be reflected by two phrases: Hè Zòng Lián Héng and Chuān Zhēn Y̌̀n Xiàn .

During the Warring States period (475B.C.221B.C.) when Chinese was divided into 7 ducal states (Qí, Chŭ, Yān, Hán, Zhào, Wèi, and Qín), artful speakers or persuasive talkers were highly respected professionals, often employed by kings or other noblepersons to carry out some particular missions with high stakes. For example, Sū Qín and Zhāng Yil, who studied strategic politics from the same teacher, turned themselves into Power Brokers and worked separately for two different super states. Sū Qín went to Qí, a super state in the east and worked for the king of Qí as a political

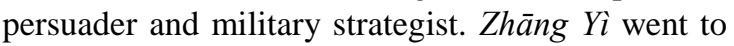
Qin, the most ferocious, aggressive, and powerful state, located in the west. When Sü Qín proposed a coalition plan and attempted to make the other six kingdoms reach an agreement against Qín, Zhāng $Y \grave{i}$ helped Qín develop diplomatic and strategic alliances with those kingdoms that were far from Qín's border. Sù Qín's plan is called "Lián Héng", meaning horizontal coalition; Zhāng Yi's plan is called "Hé Zòng", meaning vertical integration. Therefore, a historical term for such persuasive strategists was coined as "ZòngHéng Jiā", literally meaning expert of crisscross, doing jobs like strategic communication consultation. "ZòngHéng $J i \bar{a} "$ is really a grandiose term for a strategic communicator serving a crucial role in all sorts of political movements.

Although many of the Chinese historical intellectuals who have great influences over the ways of thinking among later generations, such as Confucius and Mencius, are regarded as the representatives of ZòngHéng Jiā, the uses and commonsense value of this term have become diminished since the end of Warring States Period. Shùi Kè, a persuasive talker or competent communicator has been becoming to have more negative connotation than positive.

About three hundred years ago, another metaphorical idiom from the folk community emerged to represent the role of communicator. "Chuān Zhēn Y̌̃n Xiàn", meaning threading the needle or going through with the needle and thread, were popular in folk culture before being first used by a novelist in one of his popular novels to represent the job of a female matchmaker. So this time the role of competent communicator is reified by the image of a female matchmaker.

\section{COMMON SENSES STRATEGIZE COMMUNICATION}

Self-constraint is a strategic practice that disvalues self-disclosure. In Chinese culture, selfconstraint might result from the introvert characteristics of an individual, but mostly selfconstraint in strategic communication act is regarded as not only the appropriate but intelligent act. This might be explained by the high uncertainty avoidance in a high context culture, but more profoundly such a strategic speech act has been anecdotally encoded in positive manner for thousands of years. When strategic or tactical selfconstraint becomes the established speech code and disseminates among people who share the code, the extracted value and belief actually frame people daily communication at the common sense level. 
The following three historical stories are anecdotes that created speech codes that eventually turned into metaphorical common sense and commonsense metaphors of people who are framed by them.

Wò Xīn Cháng Dăn: The literal meaning of this established phrase is crouching on the hays and tasting the gallbladder. For people from other cultures, this household idiom containing a widely known story might not make any sense, though it has already been metaphorically planted in the common sense system of the Chinese speech culture for centuries. People employ this phrase as a symbol, code, credo, criteria, standard, and rule for decision-making and advisory persuasion in many areas such as pedagogy, politics, conflict resolution (deep intervention into interference), and all sorts of everyday communication practices. Without knowing the historical story, it's not easy for people to make sense this phrase and its implications in the speech coding system of Chinese culture.

The story happened about three thousand years ago in the so-called Spring and Autumn Period (11 ${ }^{\text {th }}$ century B.C.-476B.C.) South of the Yangtze River, two ducal states, Wú and Yùe were having territorial disputes for many years. With the escalating conflicts, $W u ́$ was gradually taking the upper hand and defeated Yùe in one major campaign. The king of Yùe was captured. In order to survive, the king of Yùe pretended to be idiotically docile and even called the king of $W u$ father. Taking the foe as father indicates probably the most inferior stance and greatest humiliation. Later the king of $W u ́$ believed that the king of Yùe would never be threats to him, so he let king of Yùe go back to his territory. Since coming back from $W u ́$, the king of Yùe determined to stage a comeback and committed to fulfill a turnover. The determination and willpower might be impaired by ease and strengthened by hardship. Being afraid of forgetting the humiliation and losing the willpower, the king of Yùe made a routine of sleeping on hays every night and tasting the gallbladder every meal. The harshness of the hays and the bitterness of the gallbladder reminded him of the humiliation and reinforced his determination. By secretly rebuilding his kingdom and army, the king of Yùe eventually fulfilled his avowal of revenge and wiped out all his disgraces. The consistent hardship got paid off in the end.

This story is orally told by parents, mentors, friends, educators, and politicians over generations and generations. Crouching on hays and tasting gallbladder is not only a maxim, but a speech code guiding and framing common Chinese communication strategy.

Tāo Guāng Yăng Huì: Tāo in ancient China means leather scabbard or quiver; Guāng meaning light; Yăng, foster or incubate; Huì, darkness or discoloration. Tão Guāng Yăng Huì could be literally translated as "to hide the light and dull the color." Originally this phrase was a military term describing a move by the army at night. The shining blades of metal weapons need to be hidden by scabbards, quivers, and other covers to ensure the monotonous darkness, which is best camouflage in the evening. Later the connotation of this military term was metaphorically expanded to refer to the constraint communication style to refrain any immature revelation of ambition and competence of the communicator. This widely used phrase also contributes to the formation of the constrained characteristics of the entire Chinese nation.

A story from one chapter of a classic novel can aptly exemplify the application of such strategy in interpersonal communication between two political rivals. The historical novel, Three Kingdoms, based on the real history, is one of the four literary classics in the history of Chinese literature. Many of the characters in Three Kingdoms are household names, among which Liú Bèi and Cáo Cáo are perhaps two of the most known. Liú Bèi and Cáo Cáo are political rivals but once friends with an honorable relationship. Before Liú Bèi established his own territory to defy the domination of Cáo, he worked as a lower official under the direct commend of Cáo. Cáo found that Liú would be someone and tried to test the attributes of Liú by inviting him to a dinner together in the luscious garden of Cáo's palace. Having dinner with the contemporarily most powerful and cruelest man becomes quite a burden for Liú, who's afraid of being noticed of his political ambition by Cáo, who might kill anyone threatening him mercilessly. Liú deliberately exaggerated his uncertainty and awed excitements with a purpose to loosen Cáo's precaution against him.

After several rounds of toasts, the conversation comes to the peak. Then all of a sudden, the weather turns bad. Layers of thick black clouds seem to drop a shadow over the conversation. Unaffected by the dark clouds, Cáo becomes quite excited. He crows over his achievements and power. Then he concludes that the only one who could be a potential threat to him would be Liú. Being surprised by such a comment, Liú understands that Cáo's real purpose of such a 
comment is to test his reaction, which might reflect his mental capacity and threshold. Within seconds, Liú doesn't know how to react and then a shocking thunderclap shakes the pavilion where they are having dinner. Liú promptly throws his chopsticks and pretends that he's scared by both Cáo's words and the shocking thunderclap. Liú's feint is so natural that even Cáo with a highly suspicious trait swallows that Liú is just a faint-hearted coward that would never be a threat to him. After this meeting, Cáo's undercover agents continue to keep Liú under surveillance and find no suspicious action until finally Cáo let him run at large. Getting away from Cáo and experiencing more extreme hardships, Liú eventually established his own territory southwest of Cáo's territory and becomes the immediate and biggest threat to Cáo. This is an important episode for the formation of Three Kingdoms - Wèi (Cáo's kingdom), Shŭ (Liú's kingdom), and Wú (Sūn's kingdom), the period (222-280A.D.) when China was divided by three seigniorial states like the three legs of a tripod.

Tão Guāng Yáng Hŭi as a strategic rule and social norm has not only enabled and constrained communication at interpersonal level, but also served as a persuasive speech code utilized by the conservative force in contemporary Chinese politics. Although promoting opening policy, the conservative hope to balance the outbound movement with an intense internal control, Tāo Guāng Yáng Hŭi becomes the spiritual guidance expressed orally for all levels of government. Internal control is regarded as a more prominent value than competing exteriorly.

\section{COMMON SENSES DESCRIBE THE PROCESSES OF COMMUNICATION PERCEPTION}

Perception is perhaps the most basic stage in communication. The ways how people perceive the outside relational and social environment, to some degree, determine and reflect the styles of the communicators. In Chinese culture, people are encouraged to take a prudent stance in dealing with an environment full of sensitive relations or strangers. For example, a bride would be well advised by her mother to notice the words and observe the faces of all the family members: Chá Yán Guān Sè, meaning checking the words and observing the faces of the other becomes a conventional wisdom and rule for relational perception. Subtleties of wording and emotion alterations might be a sign of trouble in relationship and a guide for disciplining behaviors. An elderly woman lived with her daughter and her daughter's husband for many years. She was always complaining the burden of face watching in the house of the other (she doesn't take her daughter's house as her own house; sometimes she even thinks that her daughter is more of someone's wife and someone's mother than her own daughter). One of her many maxims is "watch the weather outdoor and notice the face indoor".

If we take Chá Yán Guān Sè as a more passive process, then Páng Qiāo Cè $J \grave{l}$ would be a more active process. Páng Qiāo Cè $J \bar{l}$ could be literally translated into "to knock the sides and beat the flanks." There are basically two layers of connotation in this phrase: first, it means the careful probing process in which the communicator intends to learn some underlying information on the others (similar to "beating about the bush,") such as underlying intent, real attitudes, hidden ambitions, stealthy moves, underhanded conspiracy, periphrastic personality, euphemistic meanings, and roundabout implications; second, it refers to the way to give convoluted critiques, indirect sarcasm or innuendo or insinuation. The two layers of connotations of this phrase are applied by people indistinctively because both connotations indicate a way of using verbal messages. In the probing process, the purpose is to understand or decode; in the critiquing process, the purpose is to respond or encode. Such a practice implies the prudence rule in communication in terms of both the encoding and decoding process.

Similar to the second layer of connotation of Páng Qiāo Cè $J \bar{l}$, we have another phrase that is a more typical metaphor - Hán Shā Shè Yŭng, meaning blowing poisonous sand in the face, which comes from an Chinese ancient tale of legendia about a fabulous aquatic creature called $Y u ̀$ that could shoot people from under water with poisonous sand. So this phrase is used metaphorically for describing some slanderous speech acts. The nuance between Hán Shā Shè Yüng and the second connotation of Páng Qiāo Cè $J \bar{l}$ is that the former could only be used for any negative remarks while the latter could also be used in referring to the flattering speech act.

\section{CONCLUSION}

Throughout the various stages of communication, Chinese people widely use these phrases, which have been established by usages and incorporated into the sense-making system shared 
by most Chinese. They are so common that people could get the connotations and employ them without knowing the semantic origins. The blurry images contained in these vivid metaphors contribute to the formation of such speech code system besides the phonetic effects.

Of the 13,000 established phrases, a great deal, like the above examples, serves as speech codes constituting the communication utilities, styles, practices, and common sense in Chinese culture. These phrases reflect almost every aspects of communication and have profound impacts on the formation of the social, cultural, psychological, and rhetorical paradigms of Chinese culture as a whole. Further in-depth interpretive exploration to these speech acts and their specific functional and structural features would be very interesting and meaningful in terms of understanding this culture from a more specific and therefore more perceptible perspective ([5]).

It is realistic to find an exhaustive and simple model for such an exploration. It's almost impossible to sift all the relevant speech acts of a specific culture. However, we might need a theoretical paradigm and put various aspects of culturally specific communication into a coherent network, which might help us more efficiently portray the underneath structures and commonsense gestalts of any specific culture ([9], [11], [13]).

Common sense is the gold in communication. By gold, we mean the common coin, something that can actually cause and procure the exchange of messages in communication. Like gold in currency, the value of common sense in communication lies in the interactional properties of communication. Through common sense, knowledge and skills that sustain the healthy attitudes and behaviors of communicators could be more broadly disseminated, because more people might buy in them. Intercultural studies should seek to construct commonsense understandings across cultures. In order to achieve such intercultural commonsense construction, we need to have more qualitative insights of the textures and structures, shapes and forms of common sense, particularly for those types of common sense rarely shared and realized by people from different cultures. In this case, the culturally particular common sense turns to be the culturally distinctive speech code.

\section{AUTHORS' CONTRIBUTIONS}

Yan Hai contributed significantly to the conception of the study, literature review and wrote the manuscript. Haibin Dong contributed to the analysis with constructive discussions and edited the manuscript several times.

\section{REFERENCES}

[1] Carbaugh, D. (1989). Fifty terms for talk: a cross-cultural study. In S. Ting-Toomey \& K. Korzenny (Eds.) Language, Communication and Culture (pp. 93-120). Newbury Park, CA: Sage.

[2] Crehan, K. (2011). Gramsci's concept of common sense: a useful concept for anthropologists? Journal of Modern Italian Studies 16(2), 273-287.

[3] Dobe, J. K. (2010). Kant's common sense and the strategy for a deduction. The Journal of Aestetics and Art Criticism, 68(19), 47-60.

[4] Dupuy, J. (1989). Common knowledge, common sense. Theory and Decision. 27, 3762.

[5] Ezeifeka. C. R. (2015). Grammatical metaphor: in search of proficiency in research abstract writing. Sage Open, 1-14.

[6] Geertz, C. (1993). Common sense as a cultural system. In Local Knowledge: Further Essays in Interpretive Anthropology. London: Fontana Press, pp. 73-93

[7] Hall, B \& Noguchi, M. (1995). Engaging in Kenson: an extended case study of one form of "common" sense. Human Relations, 48(10), 1129-1147.

[8] Hall, B. (2002). Among Cultures: The Challenge of Communication. Thomas: Wadsworth.

[9] Lakoff, G. \& Johnson, M. (1980). Metaphors We Live By. Chicago \& London: The University of Chicago Press.

[10] Mouffe, C. (1979). Gramsci and Marxist Theory. London: Routledge \& Kegan Paul.

[11] Nardon, L. \& Hari, A. (2021). Sensemaking through metaphors: the role of imaginative metaphor elicitation in constructing new understandings. International Journal of Qualitative Methods, 20, 1-10. 
[12] Schirato, T. \& Yell, S. (2000). Communication and Culture. St. Leonards, Australia: Sage/Allen \& Unwin.

[13] Scolari, C. A. (2012). Media ecology: exploring the metaphor to expand the theory. Communication Theory, 22(2), 204-225. 